\title{
How Thai and Chinese Young Adults Manage Time?
}

\author{
Na Chen, Pei-Luen Patrick Rau, Patpavara Suriyalaksh \\ Department of Industrial Engineering, Tsinghua University, Beijing, China \\ Email: chenn4@163.com,rpl@mail.tsinghua.edu.cn,pom_me913@hotmail.com
}

How to cite this paper: Chen, N., Rau, P.-L. P., \& Suriyalaksh, P. (2017). How Thai and Chinese Young Adults Manage Time? Psychology, 8, 717-727.

https://doi.org/10.4236/psych.2017.85046

Received: October 21, 2016

Accepted: March 28, 2017

Published: March 31, 2017

Copyright (C) 2017 by authors and Scientific Research Publishing Inc. This work is licensed under the Creative Commons Attribution International License (CC BY 4.0).

http://creativecommons.org/licenses/by/4.0/

\begin{abstract}
This paper aimed to investigate the differences in time management behaviors between Thai and Chinese young adults. Two studies were conducted among Thai and Chinese graduate and undergraduate students: a test of Macan's Time Management Behavior Questionnaire and an experiment investigating time management behaviors. Based on the results, Thai participants self-reported they had more behaviors typically related to managing time, setting goals and sequencing tasks. Chinese participants reported they had more behaviors related to work in an organized method and maintained an organized work environment and Chinese participants perceived they had better time control. On the other side, based on the results of the experiment, Chinese participants performed better in managing time.
\end{abstract}

\section{Keywords}

Time Management Behaviors, Thai and Chinese Young Adults, Cultural Difference

\section{Introduction}

China is becoming more open to the world and actively participates in international activities. With Chinese people's entering global business and politics, how to cooperate with Chinese partners and Chinese colleagues has become an importance concern for most multi-national organizations. Time management is one of the critical issues in business. Over the last 20 years, literature in the organizational management has been discussing the significance of time and the recognition of the importance of time has been growing. Orlikowski and Yates (2002) stated that awareness about the importance of time dimensions has been rising, which is due to the fact that there is a growth in global competition and immediate demands of service and services. Efficient time management usually 
results in better performance and work output, which will lead to competitive advantages.

Chinese young adults' time orientation has changed these decades of years. How this change influences their managing time has not been studies. On the other side, based on large amount of practices, Chinese people rely less on rules in work, which will also lead to their differences in time management.

China has become the second large trade partner of Thailand. The bilateral trade between the two countries has grown tremendously. Both Thailand and China have set up factories and run business in the other country. The foreign factories hire many local young adults as employees. Besides an economic connection, Thailand and China have many academic exchanges and people-people exchanges. Thailand is one of the major overseas destinations of tourism. The differences of the ability to deal with time between Thai and China people have become increasingly problematic, especially among young adults. Thai and China as a whole are experiencing major changes. Young adults in the two countries sometimes show differences from the generations before them. Hence, the research attempted to investigate the differences of time management between Thai and Chinese young adults.

Cultural comparison researches related to China usually focused on the differences between China and the Western Countries or between China and the Easter Asian countries, such as Japan and South Korea (Chen, 2004; Oetzel, Ting-Toomey, Masumoto, Yokochi, Pan, Takai, \& Wilcox, 2001). Few previous research studies focused on the differences between Thailand and China. Hence, this paper aimed to investigate the differences in time management behaviors between Thai and Chinese young adults.

\section{Literature Review}

In daily life, every person has equally 24 hours per day, but people have their own sense of time even if they share the same amount of time. Time management does not only mean to manage time but also means to manage ourselves (MacKenzie, Podsakoff, \& Fetter, 1991), which is helpful in terms of specifying the sense of everyone's time, and it is a good method to determine the effective strategy to manage people's sense of time.

The definitions of time management differs in previous related researches. Lots of researchers defined time management as techniques for managing time (Jex \& Elacqua, 1999; Macan, 1994; Macan, Shahani, Dipboye, \& Phillips, 1990). Some researchers specified the "techniques" as utilizing time effectively in order to achieve the goals in a given amount of time (Orpen, 1994, Slaven \& Totterdell, 1993; Woolfolk \& Woolfolk, 1986). Planning and allocating time are considered as two major behaviors related to time management (Burt \& Kemp, 1994; Francis-Smythe \& Robertson, 1999). Lakein (1973) stated that time management concerned the progression of specifying demands and goals, prioritizing activities, and setting up plans. Some researchers discussed time management from the aspect of recognition. They defined time management as the degree to which 
people perceive their use of time to be structured and purposive (Bond \& Feather, 1988; Strongman \& Burt, 2000; Sabelis, 2001; Vodanovich \& Serb, 1997).

Time management is practical and influences the performance and work output of both individuals and organizations. Various instruments have been designed to measure and identify factors consisting of time management. Among them, three instruments were used the most, i.e. Time Management Behavior Scale (TMBS: Macan et al., 1990), Time Structure Questionnaire (TSQ: Bond \& Feather, 1988), and Time Management Questionnaire (TMQ: Britton \& Tesser, 1991). TMBS consisted of a list of time management behaviors. TSQ was to measure the perceived ability to control time. TMQ was to measure the attitudes towards time management and behaviors related to allocating time. Among the three instruments, TMBS was the most popular.

According to the theory of TMBS, time management behaviors consist of four dimensions: time management mechanics, goal setting and priorities, preference for organization, and perceived time control. The dimension of time management mechanics concerns the typical behaviors related to time management, such as making notes and scheduling. The dimension of goal setting and prioritizing concerns the setting of the priorities of tasks to accomplish the goals. The dimension of preference for organization concerns the approaches to organize the work and work environment. The dimension of perceived time control is the most predictive dimension of behaviors.

\section{Research Framework and Research Questions}

For the purpose of this paper, two studies were designed: A test of the Time Management Behavior Questionnaire among Thai and Chinese young adults and an experiment investigating the differences in the time manage behaviors. The questionnaire is a self-report method to explore the statuses of how young adults manage time in the two countries and the experiment can provide objective data about the actual behaviors. Two research questions were proposed.

Research Question 1. What are the differences of time management behaviors between Thai and Chinese young adults?

The differences of time management behaviors included two aspects, the behaviors perceived by the young adults and the behaviors measure objectively. The two aspects of differences were investigated in this paper.

Research Question 2. What are the differences of the actual time management behaviors and self-reported behaviors for Thai and Chinese young people?

For both Thai and Chinese young adults, the perceived behaviors and their actual behaviors would be different. Research Question 2 was to investigate the differences between perceived and actual behaviors.

\section{Test of the Time Management Behavior Questionnaire}

The first study of this paper was to investigate the general differences of time management between Thai and Chinese young adults. Macan's TMBQ was selected, which is the most popular time management behavior questionnaire with 
33 items. TMBQ focused on the actual detailed behaviors people managing their time. This questionnaire consisted four subscales, i.e. time management mechanics, goal setting and prioritizing, preference for organization, and perceived time control (Macan et al., 1990). 5-point Likert scales was used to measure different levels of agreement to the items from " $1=$ strongly disagree" to " $5=$ strongly agree". Translation-retranslation was used to develop the Chinese questionnaire and Thai questionnaire.

\subsection{Participants}

The questionnaires were distributed in the universities in Bangkok and Beijing, which are the capital cities of Thailand and China. 112 Thai and 112 Chinese valid questionnaires were collected. All the participants were undergraduate or graduate students, aging from 18 to 30 years old. Gender was balanced for each sample. 60 Thai participants (53.3\%) and 52 Chinese participants (46.7\%) are male, other Thai and Chinese participants are female.

\subsection{Data Analysis}

The internal consistency of each scale according to cultures was determined using Cronbach's Alpha calculation. An alpha value of .60 or above is considered significant internal consistency for an exploratory study (Hair Jr., Anderson, Tatham, \& Black, 1995). The questionnaire's three subscales named time management mechanics, goal setting and prioritizing and preference for organization have a good reliability, and all their Cronbach's Alpha values for both Thai and Chinese samples were higher than .70. Further analysis could be conducted. The detailed results are listed in Table 1.

Independent sample t-test was used to compare the differences of time management behaviors between Thai and Chinese samples. Thai sample showed significantly higher stress on mechanics of time management, and goal setting and prioritizing (both $p<.001$ ) than Chinese sample. Thai participants perceived they had more behaviors associated managing time, setting goals, and prioritizing

Table 1. Comparisons of reported time management behavior scales between Thai and Chinese samples.

\begin{tabular}{|c|c|c|c|c|c|c|c|c|}
\hline \multirow{2}{*}{ Sub-scale } & \multicolumn{3}{|l|}{ Thai } & \multicolumn{3}{|l|}{ Chinese } & \multirow{2}{*}{$\mathrm{t}$} & \multirow{2}{*}{$p$} \\
\hline & Cronbach's Alpha & M & $\mathrm{SD}$ & Cronbach's Alpha & $\mathrm{M}$ & $\mathrm{SD}$ & & \\
\hline $\begin{array}{l}\text { Time management } \\
\text { mechanics }\end{array}$ & .705 & 3.32 & .33 & .763 & 2.82 & .66 & 7.269 & $<.001$ \\
\hline $\begin{array}{l}\text { Goal setting and } \\
\text { prioritizing }\end{array}$ & .773 & 3.49 & .57 & .785 & 2.67 & .60 & 10.547 & $<.001$ \\
\hline $\begin{array}{l}\text { Preference for } \\
\text { organization }\end{array}$ & .721 & 2.77 & .32 & .743 & 3.00 & .66 & -3.256 & .001 \\
\hline $\begin{array}{l}\text { Perceived control } \\
\text { of time }\end{array}$ & .514 & 2.88 & .40 & .585 & 3.10 & .61 & -3.163 & .002 \\
\hline
\end{tabular}

Result is significant at the .05 level. 
tasks. Chinese sample showed significantly higher stress on preference for organization $(p=.001)$. They perceived themselves more to work in an organized approach and maintain an organized work environment. Chinese sample perceived better control of time than Thai sample $(p=.002)$. The detailed results are listed in Table 1.

\section{Experiment Investigating Time Management}

Significant differences were found in time management behaviors between Thai and Chinese young adults. An experiment was designed to objectively measure their time management behaviors.

\subsection{Independent Variables, Dependent Variables and Covariates}

The nationality was the only independent variables in this experiment, which contained two levels, Thai and Chinese.

TMBQ provided some typical behaviors of time management, such as sequencing tasks, prioritizing tasks, setting goals, and utilizing waste time. This paper chose to measure five time management behaviors as the dependent variables in order to investigate the performance of both Thai and Chinese young adults. The behaviors to be measured were 1) whether finishing all tasks, 2) whether sequencing tasks at the beginning, 3 ) whether prioritizing special tasks, 4) whether utilizing time while waiting, and 5) whether switching tasks during the experiment without reasons. The first recorded behavior was to measure the participants' performance of time management. The second, third and fourth recorded behaviors were to measure specific and typical time management behaviors. The fifth recorded behaviors were to measure participants' behaviors while interrupted.

As a covariate, perceived control of time was measured through the means of questionnaire. In the Time Management Behavior Scale, the subscale of perceived control of time could predict behaviors the best (Macan et al., 1990). To reduce participants' workload, this experiment only measured this subscale instead of the whole scale.

Demographic questions including age, gender, nationality, school, and major were also measured.

\subsection{Tasks and Experiment Procedure}

Ten simple tasks were designed for time management experiment: nine "regular" tasks and one "special" task. These tasks were simple enough to avoid the influences of tasks themselves on participants' performance. These tasks covered several different abilities of participants, including writing, operating, calculating, painting, and decision making. The numbers in parenthesis shown below after each task indicates the minutes expected to finish each task. The total time expected to finish all ten tasks was 40 minutes. The regular tasks were copying an article (6), finding vocabulary (5), cutting paper (3), solving a Jigsaw Puzzle (4), calculating (6), grouping cards (2), toasting pieces of bread (3), eating the 
toasted bread (2), and topping a ping pong ball (5). The "special" task was coloring a picture (4).

At the beginning of the experiment, participants were only informed to finish the regular tasks. They could choose the sequences to do tasks. The sequences of the regular tasks to be showed to participants were random, in order to avoid the influences on the sequences of participants' doing tasks. Besides, they were told that the task of calculating must be submitted at the end of the twentieth minute, and the task of copying an article must be submitted at the end of the thirtieth minute.

The special task was suddenly assigned to the participants at the end of the 10th minute, in order to measure participants' ability to deal with multi-tasks and whether they would review the schedules and goals.

However, all ten tasks were provided to participants with "stars" indicating the importance of the task. The numbers of stars ranged from five to one. The task with more stars was more important so it had higher priority. Among the tasks, the task of calculating should be submitted at the end of the 20th minute and the task of copying the article should be submitted at the end of the 30th minute.

The task of toasting bread needed participants to wait for two minutes. Their behaviors during the waiting time were recorded as the evidence of abilities to manage time.

After finishing the tasks, a short interview was held to double checked whether the participants actually performed the five time management behaviors which this experiment aimed to measure. Reasons and thoughts about the participants' behaviors were also reviewed though the short interview.

\subsection{Participants}

30 participants were recruited: 15 Thai and 15 Chinese. All the participants were undergraduate or graduate students in Beijing, aging from 18 to 30 years old. The average age was 24.4 for Thai participants and 22.27 for Chinese participants. Gender was balanced for each sample: 1) $53.3 \%$ Thai participants are male and 2) $46.7 \%$ Chinese participants are male. To reduce the influence of culture adaptation, the Thai participants had been in Beijing no more than three months.

\subsection{Data Analysis}

Among the five measured time management behaviors, significantly more Chinese participants finished all the tasks and set goals before doing tasks (both $p$ $=.027)$. Five Thai participants continued current tasks although interrupted by the special task-the frequency was significantly higher than Chinese participants $(p=.042)$. All Thai and Chinese participants utilized the waiting time of coasting bread. The majorities of both Thai and Chinese samples chose to do the time-limited tasks and no significant difference was found between the two samples $(p=.169)$. The detailed results are listed in Table 2 .

Based on the result of two independent samples t-test of the scale of perceived 
Table 2. Comparison of time management behaviors during the experiment between Thai and Chinese participants.

\begin{tabular}{|c|c|c|c|c|c|}
\hline \multirow{2}{*}{ Recorded Behaviors } & \multicolumn{2}{|c|}{ Thai } & \multicolumn{2}{|c|}{ Chinese } & \multirow{2}{*}{$p^{*}$} \\
\hline & Frq. & Ratio & Frq. & Ratio & \\
\hline Finishing all tasks & 3 & $20 \%$ & 10 & $67 \%$ & .025 \\
\hline $\begin{array}{l}\text { Planning sequences to do tasks at the beginning } \\
\text { of the experiment }\end{array}$ & 5 & $33 \%$ & 12 & $80 \%$ & .025 \\
\hline $\begin{array}{l}\text { Choosing to do the tasks of calculating and } \\
\text { copying article first }\end{array}$ & 10 & $67 \%$ & 14 & $93 \%$ & .169 \\
\hline Doing other tasks while waiting for toasted bread & 15 & $100 \%$ & 15 & $100 \%$ & - \\
\hline Continuing tasks although interrupted & 5 & $33 \%$ & 0 & 0 & .042 \\
\hline
\end{tabular}

Result is significant at the 0.05 level; ${ }^{\star}$ Fisher's Exact Chi-square Test.

time control, no significant difference was found between Thai and Chinese participants $(\mathrm{t}=.262, p=.796)$.

\section{Discussion}

According to the results of the test of TMBQ, Thai respondents are more likely to perform behaviors typically related to time management, such as making notes and scheduling, and more likely to set the priorities of tasks to accomplish their goals. On the other side, Chinese respondents preferred more to work in an organized method and maintain an organized work environment. Chinese respondents perceived they had better control of time than Thai respondents. According to the results of the experiment investigation time management behaviors, while doing regular tasks, Chinese participants performed better than Thai participants because significantly more Chinese participants finished all tasks and planned sequences to do tasks at the beginning of the experiment. However, Chinese participants were more easily interrupted by the special task.

The results of the questionnaire and the experiment were partially contractin the questionnaire Thai respondents reported they were more likely to set goals and prioritize tasks, while in the experiment, Chinese participants performed better in prioritizing tasks.

The self-report questionnaire reflects respondents' beliefs about their own time management behaviors and abilities. Based on the results of the post-interview in the experiment, Thai participants tended to work based on their preference and emotion rather than unwilling to do the tasks. In contrast, Chinese participants tended to plan their tasks in advance depending on the importance rather than preference. The lifestyles of Thai young adults are highly flexible which seems to lead to poorer performance of time management. Chinese young adults face high competition because of the large population, so they have a high level of self-control and self-regulation.

The high competition and social uncertainty in China is also a reason why Chinese respondents in the test of TMBQ reported they perceived better control 
of time. Chinese young adults should plan their time more carefully to face high such a competitive and uncertain society.

This paper was just an explorative study to find potential differences in time management behaviors between Thai and Chinese participants. The small sample sizes in the experiment limited the further analysis of participants' behaviors. According to the results of both the questionnaire and experiment, although China and Thailand are Asian neighbors and they are considered closely linked in lots of social, cultural and historical issues, significant differences between the young adults were found.

\section{Conclusion}

The purpose of the research was to investigate the differences in time management behaviors between Thai and Chinese young adults, including the differences in both self-reported behaviors and actual behaviors. Two studies were conducted: 1) a test of the Time Management Behavior Questionnaire, and 2) an experiment investigating time management behaviors

According to the results of the test of TMBQ, Thai respondents had significantly more behaviors typically related to managing time and setting goals and prioritizing tasks. Chinese respondents had significantly more behaviors related to work in an organized method and maintain an organized work environment. Besides, Chinese respondents showed significantly higher perceived ability of time control.

On the other side, the results of the experiment showed that Chinese participants performed significantly more behaviors related to setting goals and sequencing tasks. Thai participants were less interrupted while doing multi-tasks.

Based on this explorative work, further study can be conducted to investigate the cultural influences on time management behaviors between Thai and Chinese young adults.

\section{Fund}

This study was funded by a National Natural Science Foundation China grant 71661167006.

\section{References}

Bond, M. J., \& Feather, N. (1988). Some Correlates of Structure and Purpose in the Use of Time. Journal of Personality and Social Psychology, 55, 321. https://doi.org/10.1037/0022-3514.55.2.321

Britton, B. K., \& Tesser, A. (1991). Effects of Time-Management Practices on College Grades. Journal of Educational Psychology, 83, 405. https://doi.org/10.1037/0022-0663.83.3.405

Burt, C. D., \& Kemp, S. (1994). Construction of Activity Duration and Time Management Potential. Applied Cognitive Psychology, 8, 155-168. https://doi.org/10.1002/acp.2350080206

Chen, M. (2004). Asian Management Systems: Chinese, Japanese and Korean Styles of Business. Cengage Learning EMEA, Hampshire. 
Francis-Smythe, J. A., \& Robertson, I. T. (1999). On the Relationship between Time Management and Time Estimation. British Journal of Psychology, 90, 333-347. https://doi.org/10.1348/000712699161459

Hair Jr, J., Anderson, R., Tatham, R., \& Black, W. (1995). Multiple Discriminant Analysis. Multivariate Data Analysis with Readings (pp. 178-237). Englewood Cliffs, NJ: Prentice-Hall International Inc.

Jex, S. M., \& Elacqua, T. C. (1999). Time Management as a Moderator of Relations between Stressors and Employee Strain. Work \& Stress, 13, 182-191. https://doi.org/10.1080/026783799296138

Lakein, A. (1973). How to Get Control of Your Time and Your Life. New York, NY: P.H. Wyden.

Macan, T. H. (1994). Time Management: Test of a Process Model. Journal of Applied Psychology, 79, 381. https://doi.org/10.1037/0021-9010.79.3.381

Macan, T. H., Shahani, C., Dipboye, R. L., \& Phillips, A. P. (1990). College Students' Time Management: Correlations with Academic Performance and Stress. Journal of Educational Psychology, 82, 760. https://doi.org/10.1037/0022-0663.82.4.760

MacKenzie, S. B., Podsakoff, P. M., \& Fetter, R. (1991). Organizational Citizenship Behavior and Objective Productivity as Determinants of Managerial Evaluations of Salespersons' Performance. Organizational Behavior and Human Decision Processes, 50, 123-150.

Oetzel, J., Ting-Toomey, S., Masumoto, T., Yokochi, Y., Pan, X., Takai, J., \& Wilcox, R. (2001). Face and Facework in Conflict: A Cross-Cultural Comparison of China, Germany, Japan, and the United States. Communication Monographs, 68, 235-258. https://doi.org/10.1080/03637750128061

Orlikowski, W. J., \& Yates, J. A. (2002). It's about Time: Temporal Structuring in Organizations. Organization Science, 13, 684-700. https://doi.org/10.1287/orsc.13.6.684.501

Orpen, C. (1994). The Effect of Time-Management Training on Employee Attitudes and Behavior: A Field Experiment. The Journal of Psychology, 128, 393-396. https://doi.org/10.1080/00223980.1994.9712743

Sabelis, I. (2001). Time Management: Paradoxes and Patterns. Time \& Society, 10, 387-400.

Slaven, G., \& Totterdell, P. (1993). Time Management Training: Does It Transfer to the Workplace? Journal of Managerial Psychology, 8, 20-28. https://doi.org/10.1108/02683949310024432

Strongman, K. T., \& Burt, C. D. B. (2000). Taking Breaks from Work: An Exploratory Inquiry. The Journal of Psychology, 134, 229-242 https://doi.org/10.1080/00223980009600864

Vodanovich, S. J., \& Seib, H. M. (1997). Relationship between Time Structure and Procrastination. Psychological Reports, 80, 211-215. https://doi.org/10.2466/pr0.1997.80.1.211

Woolfolk, A. E., \& Woolfolk, R. L. (1986). Time Management: An Experimental Investigation. Journal of School Psychology, 24, 267-275. 


\section{Appendix}

\section{Time Management Behavior Questionnaire}

Time management mechanics

1. I carry a notebook to write down notes and ideas.

2. To avoid interruptions and distractions, I find quite and private places.

3. I schedule activities at least a week in advance.

4. When I find that I am frequently contacting someone, I record that person's name, address, and phone number in a special file.

5. I block out time in my daily schedule for regularly schedules events.

6. I write down notes to remind myself of what I need to do.

7. I make a list of all things to do each day and check off each task as it is accomplished.

8. I carry an appointment book with me.

9. I keep daily log of my activities.

10. If I know I have to spend time waiting, I bring along something I can work on Goal setting and prioritizing

11. I set short-term goals for what I want to accomplish in a few days or weeks.

12. I set deadlines for myself when I set out to accomplish a task.

13. I look for ways to increase the efficiency with which I perform my work activities.

14. I finish top priority tasks before going to less important ones.

15. I review my daily activities to see where I am wasting my time.

16. During a workday, I evaluate how well I am following the schedule I have set down for myself.

17. I set priorities to determine the order, in which I will perform tasks each day.

18. I break complex, difficult projects down into smaller manageable tasks.

19. When I decide on what I will try to accomplish in the short-term, I keep in mind my long-term objectives.

20. I review my goals to determine if they need adapting.

Preference for organization

21. At the end of the day, I leave a clear, well-organized workspace.

22. When I make a to-do-list at the beginning, it is forgotten or set aside by the end of the day.

23. I can find things I need for my work easily when my workspace is messy and disorganized than when it is neat and organized.

24. The time I spend scheduling and organizing my workday is a wasted time.

25. My days are too unpredictable for me to plan and manage my time to any great extent.

26. I have some of my creative ideas when I am disorganized.

27. I try to finish most preferred task before going to less liked ones.

28. When I am somewhat disorganized, I am better able to adjust to unexpected events.

Perceived control of time

29. I underestimate the time that it will take to accomplish task. 
30. I feel that I can control my time.

31. I must spend a lot of time on important tasks.

32. I find it difficult to keep to a schedule because others take me away from my work.

33. I find myself avoiding doing tasks that I don't like but these tasks must be done.

Submit or recommend next manuscript to SCIRP and we will provide best service for you:

Accepting pre-submission inquiries through Email, Facebook, LinkedIn, Twitter, etc. A wide selection of journals (inclusive of 9 subjects, more than 200 journals)

Providing 24-hour high-quality service

User-friendly online submission system

Fair and swift peer-review system

Efficient typesetting and proofreading procedure

Display of the result of downloads and visits, as well as the number of cited articles Maximum dissemination of your research work

Submit your manuscript at: http://papersubmission.scirp.org/

Or contact psych@scirp.org 